Volume 9. No. 8, August 2021

International Journal of Emerging Trends in Engineering Research

Available Online at http://www.warse.org/IJETER/static/pdf/file/ijeter23982021.pdf

https://doi.org/10.30534/ijeter/2021/23982021

\title{
Investigation Ability of Two-Dimensional Nano Materials for Detection Toxic Gases
}

\author{
Hussein A. Madlool ${ }^{1}$, Ahmed Hashim², Mohammed A. Al-Seady ${ }^{3 *}$ and Hayder M. Abduljlil ${ }^{4}$ \\ ${ }^{1}$ Al-Mustaqbal University College, Radiological Techniques Department, 51001 Hillah, Babil, Iraq. \\ ${ }^{2}$ University of Babylon, College of Education for Pure Sciences, Department of Physics, Iraq \\ ${ }^{3}$ Unversity of Babylon-Environmental Research and Center Studies-Hilla-Iraq, wellmsc@ gmail.com \\ ${ }^{4}$ University of Babylon-Collage of Science-Physics Department-Hilla-Iraq.
}

\begin{abstract}
In this study, pure graphene nano-ribbon were used to detect toxic gases under study, which are carbon monoxide, hydro cyanide and methane. The study focused on describing graphene nano-ribbons as sensors for these gases and their use in environmental applications. Quantitative computing methods have been used to calculate the properties of the ground state by density function theory (DFT) and the properties of the stationary state, it was computed by using the time-dependent Schrödinger equation. Ground-state calculations include geometric optimization, total energy, ionization potential, electron affinity, molecular orbit energies, energy gap, adsorption energy and infrared spectrum. Whereas, the time-dependent Schrödinger equation calculations included the UV-Visible spectrum calculations, in order to characterize them as detectors of toxic gases. It was found by studying the adsorption of pure graphene nano-ribbons is sensitive to carbon monoxide, clearly and higher than
\end{abstract}

Graphene is the name given to a single layer of graphite, made up of $\mathrm{sp}^{2}$ hybrids carbon atoms arranged in honeycomb lattice, it consists of two interpenetrating triangular sub-lattice A and B Figure (1) and is a basic building block for carbon allotropes of other dimensionalities similar to fullerenes and carbon nanotubes[1]. Graphene as a two-dimensional connected carbon sheet is an excellent material that has exceptional properties such as superior surface to volume fraction, little electrical noise and outstanding transport properties[2]. Graphene has more superior efficiency in addition to its unique two-dimensional structure and has unique chemical properties such as outstanding electrical, optical and mechanical properties. Due to its excellent

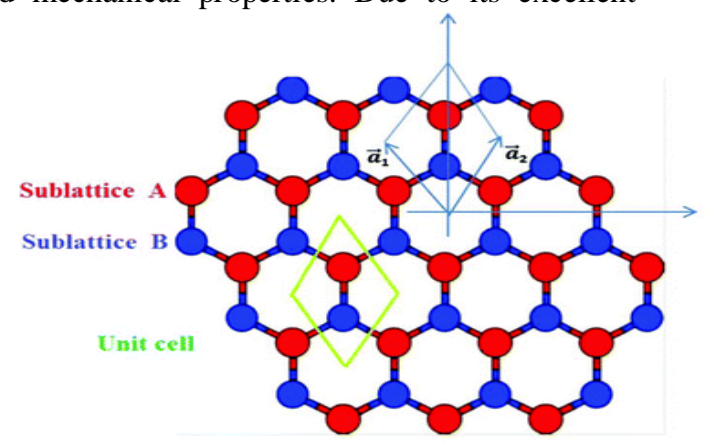

hydro cyanide and methane. Also, as a result of the chemical reaction, there is a clear effect on the values of the energy gap, the ionization potential, and other associated properties. The effect of the chemical reaction continues at an adsorption distance of 2 angstroms from the surface. As for the infrared radiation calculations, it showed that the appearance of free radicals of adsorbed gases on the surface of the nano-ribbons is a clear evidence of the occurrence of chemical reaction with high energy. Through the results, the calculations of the UV-visible spectrum showed a clear shift in the computed spectrum at the ranges of high-energy interaction (34.0385-22.3212) and (15.7433-3.3246) electron volts for both nano-ribbons.

Key words: Adsorption energy, Graphene, TwoDimensional Martials, Chemical adsorption

\section{1-INTRODUCTION}

properties, graphene has been commonly used in a number of ways, such as energy generation, spintronics and field effects transistor (FET)[1]. Graphene has also been proven to have possible uses in detection molecules, both experimental and theoretical. Graphene may be chosen as a novel material for adsorption and desorption due to its low dimensions and wide surface area process[3]. Graphene is a zero band gap semiconductor with its valence and conduction bands touching in corner of the Brillion zone in called Dirac points[4]. Development of graphene based electronics depends on ability to open a tunable band gap, various approaches have been developed to fabricate highperformance graphene device by engineering their band gaps so as to improve their semiconducting properties[5].

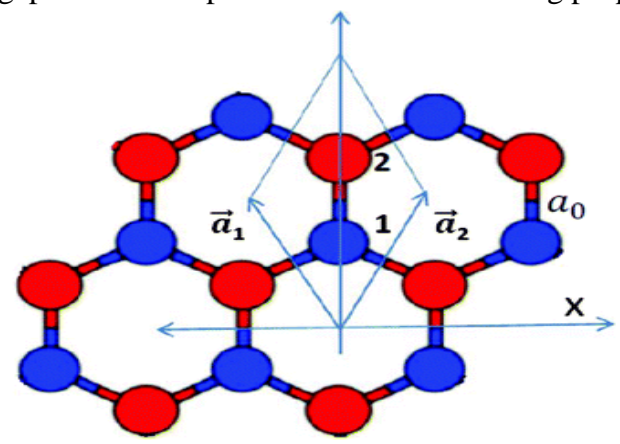

Figure 1: Schematic presentation graphene sheet. Each Braves lattice unit cell including two nonequivalent sites[5]. 
Two dimensional materials (Graphene and derivatives) possess tunable electronic characteristic and find potential application, the two dimensional nanomaterials play an

\section{2- ADSORPTION MECHANSIM AND IT TYPES}

Adsorption mechanism is considered one of the important kinds of surface science, it is defined as process when molecule and ions called adsorbate stick on surface of a solid called adsorbent[7]. Adsorbate attached on adsorbent surface, consequently the degree of freedom and limited surface free energy decreases because unbalanced forces between two reactors[8]. The transition of the adsorbent from the liquid phase to the solid phase continues until the balance between the amount of adsorbent contained in the adsorbent and the amount of adsorbent remaining in the solution is achieved[9]. In general it is classified to chemical and physical adsorption

\section{3- ADSORPTION PROCESS IN 2-D MATERIALS.}

Since solid-states gas sensor has high sensitivity, wide range of application and low cost according to[13], so a new generation of gas sensors has been demonstrated using carbon nanotubes (CNTs) and semi-conductor nanowire in the past few years[14]. CNTs seem likely to be a great nanoscale sensor because of its fast response time and high sensitivity at room temperature[15]. Similar to good sensor properties of CNTs, graphene considered to be an excellent sensor material due its special properties such as two dimensional structure maximizing the interaction of adsorbates on the layer, low Johnson noise and few crystal defect[16].

Graphene sample has been reported to be used a very sensitive gas sensor with the possibility of detecting dioxide nitrogen gas molecule $\left(\mathrm{NO}_{2}\right)$ molecules, which has encouraged the theoretical examination of the sensing properties of graphene[17]. It was demonstrated that donor or acceptor molecule on graphene can significantly change

\section{4- LITERATURESURVEY}

Ssomayeh F. Rastegar, et al., investigated in (2013) sensitivity of HCN towered graphene doped by aluminum and silicon atoms. The researchers used DFT method to computed energic and geometrical properties. For pure graphene nano-ribbon $\mathrm{HCN}$ gas molecule adsorbed physically. After adding metal atom geomatical structure of pure graphene changed, surface of it starching in bond length in position of doped atoms. Adsorption energy of $\mathrm{HCN}$ across aluminum-graphene (AlG) was greater than silicon-graphene (SiG). final result show that $\mathrm{AlG}$ structure promising to detecting $\mathrm{HCN}$ more acceptable than $\mathrm{SiG}[21]$.

Xian-Ping Chen, et al., in (2015) investigated $\mathrm{CH}_{4}$ adsorption in pure graphene and some dopant atoms using

\section{5- CCOMPUTATINAL DETAILS.}

Nano tube modular is used in this study to generate graphene nano-ribbon structure $\mathrm{n}=\mathrm{m}=3$ and tube length 1 $\mathrm{nm}$. Export structure to Gaussian 5.0 version for display system. Then exporting the input data to Gaussian 09, this essential role in the development of nano electronic device applications owing to their excellent electronic properties such as rapid switching and high mobility[6].

mechanism[10]. In chemical adsorption high amount of electron transport between two reaction system, high energy rises during this process it ranged from 40-800 $\mathrm{kJ} / \mathrm{mol}$, and this process was irreversibly. All of these result back to presence chemical bond between adsorbent and adsorbate[11]. In physical adsorption weak van der Waals interaction appear, no electron exchanges between them. Small amount of energy rises it ranged from 5-40 $\mathrm{kJ} / \mathrm{mol}$. One important factor of reducing energy is absence chemical bonding. Finally physical adsorption was more acceptable on multi-layer system[12].

the electronic properties, by using DFT method[18]. Besides when gases molecules adsorbed on graphene sheet there appears changes in the resistivity, which makes it possible for graphene to be solid state sensor to detect gas molecules. Capability of adsorption and lofty surface-tovolume fraction of graphene make it an ideal gas-sensing material. Recently, the adsorption of different atmospheric gases on graphene (as an active surface) has been studied experimentally and theoretically[19]. Adsorption process in pure graphene is not too varied. Therefore, regardless of some exception, it may not be the best choice to use pure graphene for adsorption mechanism of gas molecules. To conquer the insensitivity of these molecules on pure graphene, doped graphene will be appreciated because of the formation three dimensional structure, it is established that higher sensitivity

of graphene toward different molecules could be achieved by doping metals[20].

DFT calculation. Relaxation distance computed is $3.56 \AA$. this study proved gas molecule interaction physically[22]. Esmail Vessally, et al., in (2017) studied adsorption energy of aspirin drug boron-nitride in pure and doped formula. Researchers used DFT method to study interaction of aspirin drug molecule across surface of born-nitride nano cage. For pure state adsorption energy ranged of -10.2 to $32.6 \mathrm{kcal} / \mathrm{mol}$. By adding aluminum atom to structure adsorption energy increasing and it ranged from -42.9 to 75.5. It is clearly that doped boron-nitride by aluminum atom modification adsorption energy and thermal properties. Also, UV spectra changed from blue shifting respect to pure boron-nitride nano cage to red shifting because doping process[23].

is to compute geometrical and electronical proprieties, also adsorption energy $\left(\mathrm{E}_{\mathrm{ad}}\right)$. $\mathrm{E}_{\mathrm{ad}}$ can computed from following equation.

$\mathrm{E}_{\mathrm{Ad}}=\mathrm{E}\left({ }_{\text {Gas }+ \text { Rib }} \cdot\right)-\left(\mathrm{E}\left({ }_{\text {Gas }}\right)+\mathrm{E}(\right.$ Rib.$\left.)\right)$ 
Where $\mathrm{E}_{\mathrm{Ad}}$ represent adsorption energy, $\mathrm{E}_{(\mathrm{Gas}+\mathrm{Rib} .)}, \mathrm{E}_{(\mathrm{Gas})}$ and $\mathrm{E}_{\mathrm{E}(\mathrm{Rib} .)}$ are total energy for mixture adsorption, gas molecule and isolated nano-ribbon, respectively. UV-

\section{6- RESULTS AND DISSCUSION \\ 6-1 GEOMATRICAL PROPRTIES AND ELECTRONIC STRACTURE.}

Geometrical characteristics summarized on bond length and angle between atoms computed for graphene nanoribbon when toxic gas molecule absence. Figure (2) lists the geometry structure for pure graphene nano-ribbon. Bond length for $\mathrm{C}-\mathrm{C}, \mathrm{C}=\mathrm{C}, \mathrm{C}=\mathrm{C}$ (aromatic) and $\mathrm{C}-\mathrm{H}$ are (1.4555), (1.3661), (1.4305) and (1.0859) ^ values of bond length are agreements with past study[25]. Angles between
Visible properties are computed by the time dependingdensity function theory. Basis set used in present study was 6-31G and hybrid function B3LYP[24].

Table 1: Properties for pure graphene and boron-nitride nano-ribbon.

\begin{tabular}{|c|c|}
\hline Property & Graphene nano-ribbon \\
\hline \hline Et (a.u.) & -1916.0381 \\
\hline \hline HOMO (eV) & -4.780973 \\
\hline \hline LUMO (eV) & -2.247084 \\
\hline \hline Eg (eV) & 2.533888 \\
\hline IP (eV) & 4.780973 \\
\hline \hline EA (eV) & 2.247084 \\
\hline
\end{tabular}

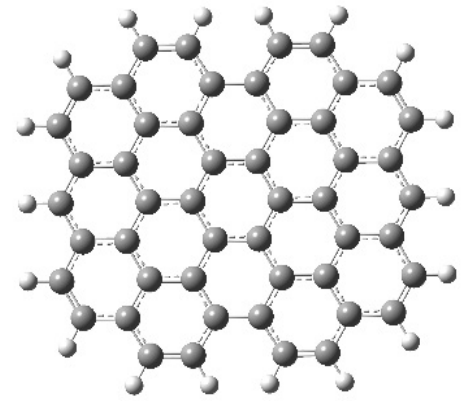

Figure 2: Represents graphene nano-ribbon structure, white ball is hydrogen, grey ball is carbon, respectively.

\section{6-2 FULL RELAXATION STRACTURE AND ADSORPTION ENERGY.}

Three gases are used in this part mono carbon oxide $(\mathrm{CO})$, hydro cyanide $(\mathrm{HCN})$ and methane $\left(\mathrm{CH}_{4}\right)$ that interact with graphene nano-ribbon. First step determines full relaxation between gas molecule and graphene nano-ribbon and determine minimum energy of stability, also type of adsorption at these distances. Second step change

adsorption distance between gas molecule and graphene nano-ribbon. Figure (3) shows full relaxation structure between two reactors. Table (2) shows full relaxation distance and adsorption energy computed by DFT. Results indicate all gases have physical adsorption at equilibrium distance.

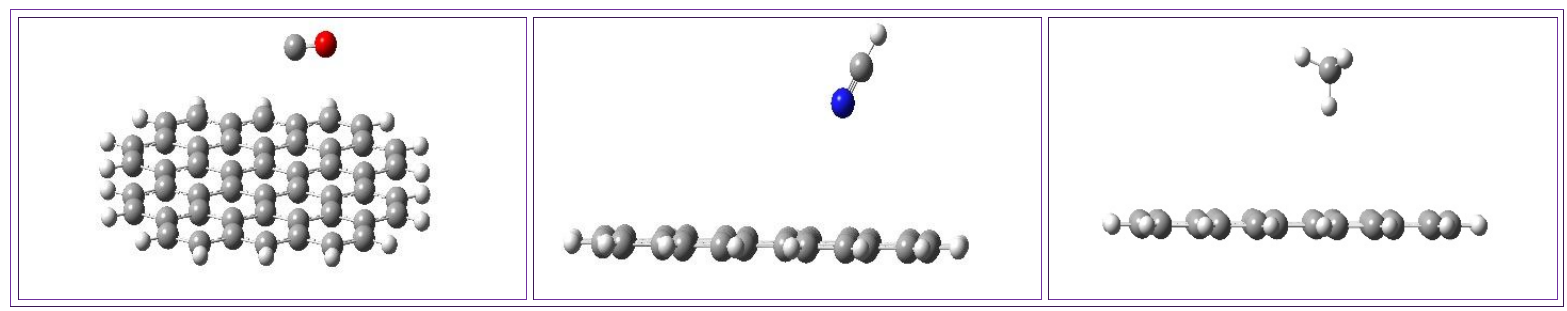

Figure 3: Shows full relaxation structure for gas molecule adsorbed on graphene surface are $\mathrm{CO}, \mathrm{HCN}$ and $\mathrm{CH}_{4}$ respectively. 
Hussein A. Madlool et al., International Journal of Emerging Trends in Engineering Research, 9(8), August 2021, 1170 - 1178

Table 2: Shows full relaxation distance and adsorption energy for system under study.

\begin{tabular}{|c|c|c|}
\hline Gases & Adsorption energy eV & Full relaxation dis. $\AA$ \\
\hline $\mathrm{CO}$ & -0.05 & 3.88 \\
\hline $\mathrm{HCN}$ & -0.029 & 3.86 \\
\hline $\mathrm{CH}_{4}$ & 0.0027 & 3.55 \\
\hline
\end{tabular}

Now, the study effect changes distance on adsorption energy to enhance the sensitivity of graphene nano-ribbon for these gases. Table (3) listed adsorption energy and distance between gas molecule and nano system and splitstep equal $0.5 \AA$ for $\mathrm{CO}$ gas molecule adsorption distance that far from the surface. Indicate that graphene sensitive to gas molecule but in a small amount of energy transfer between them this clear for distance 3.5 to 2 . Distance 2 to $1 \AA$ adsorption energy increasing and nano system began sense to a gas molecule. Increasing in adsorption energy led to the formed bond between $\mathrm{C}$ atom in graphene ribbon and $\mathrm{C}$ atom in a gas molecule. Bonding led to chemical adsorption that rising high adsorption energy. Energy absolute value increasing from 3.9809 to $34.0385 \mathrm{eV}$. HCN gas molecule in the same distance indicates that in physical interaction rises small energy resulting from adsorption mechanism and this appears in distance 4 to $2 \AA$. Suddenly adsorption energy increasing reaches absolute energy value equal $19.298 \mathrm{eV}$, this value smaller than $\mathrm{CO}$ adsorption energy in a chemical process. This increase in energy because loan pair formed between $\mathrm{C}$ in graphene ribbon and $\mathrm{N}$ related to a gas molecule. $\mathrm{CH}_{4}$ gas molecule reaction with graphene but in low activity compared with the past two gases. The absolute energy value increasing from zero to $2 \mathrm{eV}$ at distance 4$1.5 \AA$ all these distances refer.

\begin{tabular}{|c|c|c|c|}
\hline $\begin{array}{l}\mathrm{D} \\
(\AA) \\
(\mathrm{A})\end{array}$ & CO & $\mathrm{HCN}$ & $\mathrm{CH}_{4}$ \\
\hline 1 & 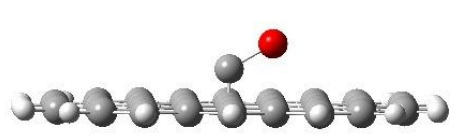 & - & 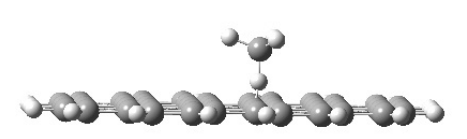 \\
\hline 1.5 & $300=0=0=0=0$ & 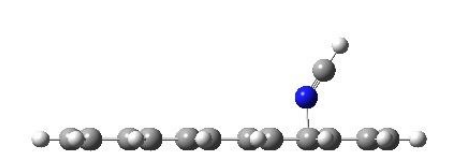 & 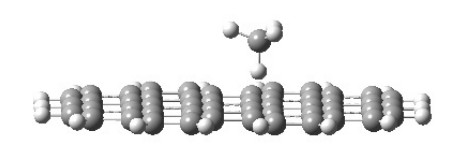 \\
\hline 2 & $\begin{array}{c}0^{0} \\
10000000000\end{array}$ & 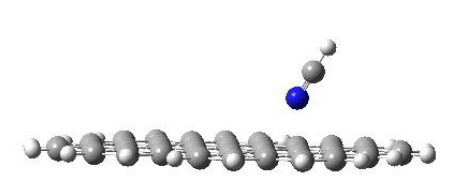 & 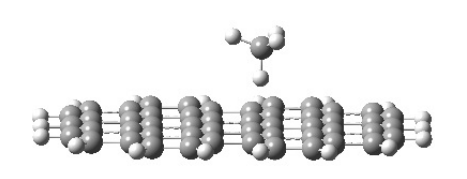 \\
\hline 2.5 & 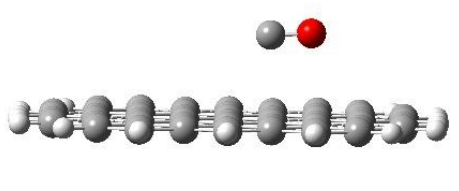 & 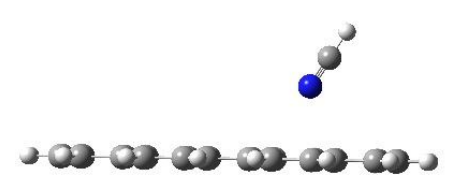 & 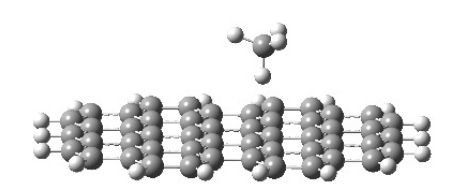 \\
\hline 3 & $\begin{array}{c}00 \\
200-00-00000\end{array}$ & 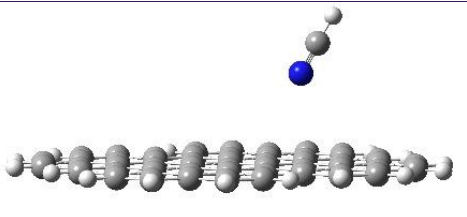 & 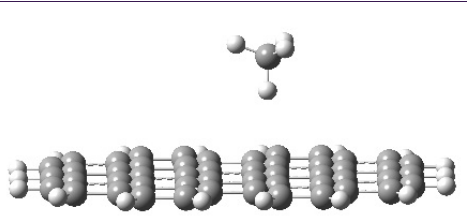 \\
\hline
\end{tabular}


Hussein A. Madlool et al., International Journal of Emerging Trends in Engineering Research, 9(8), August 2021, 1170 - 1178

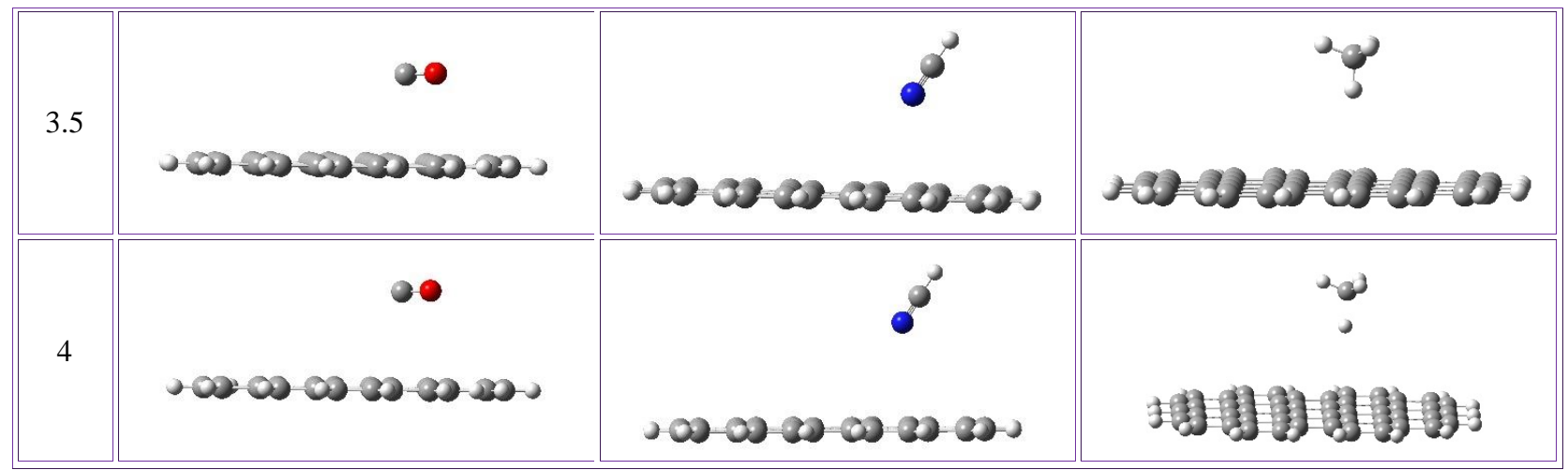

Figure 5: Represents geometrical orientation of gas molecule as a function of adsorption distance.

to physical adsorption. Chemical adsorption appears only when bonds formed between $\mathrm{H}$ related to gas with $\mathrm{C}$ of graphene nano-ribbon. Finally, more negative energy more stable system. Negative energy value refers to the interaction was exothermic[26]. Results show that CO gas molecule have high adsorption energy because strong difference in the electronegativity of $\mathrm{C}$ and $\mathrm{O}$ atoms. Figure (4) represents adsorption curves for gases understudy. Figure (5) represent geometrical structure for adsorption gases molecule across surface of $\mathrm{G}$ nanoribbon

system

Table 3: Lists of computed adsorption energy in electron volt unit (eV).

\begin{tabular}{|c|c|c|c|}
\hline \multicolumn{1}{|c|}{$(\AA)}$. & $\mathrm{CO}$ & $\mathrm{HCN}$ & $\mathrm{CH}_{4}$ \\
\hline 1 & -34.0385 & -19.2980 & -7.3088 \\
\hline 1.5 & -22.3212 & -5.9456 & -2.1496 \\
\hline 2 & -3.9809 & -1.8585 & -0.5278 \\
\hline 2.5 & -0.9224 & -0.4000 & -0.1034 \\
\hline 3 & -0.1659 & -0.07891 & -0.01360 \\
\hline 3.5 & -0.0163 & -0.03265 & 0.001532 \\
\hline 4 & 0.00216 & -0.02993 & 0.002721 \\
\hline
\end{tabular}

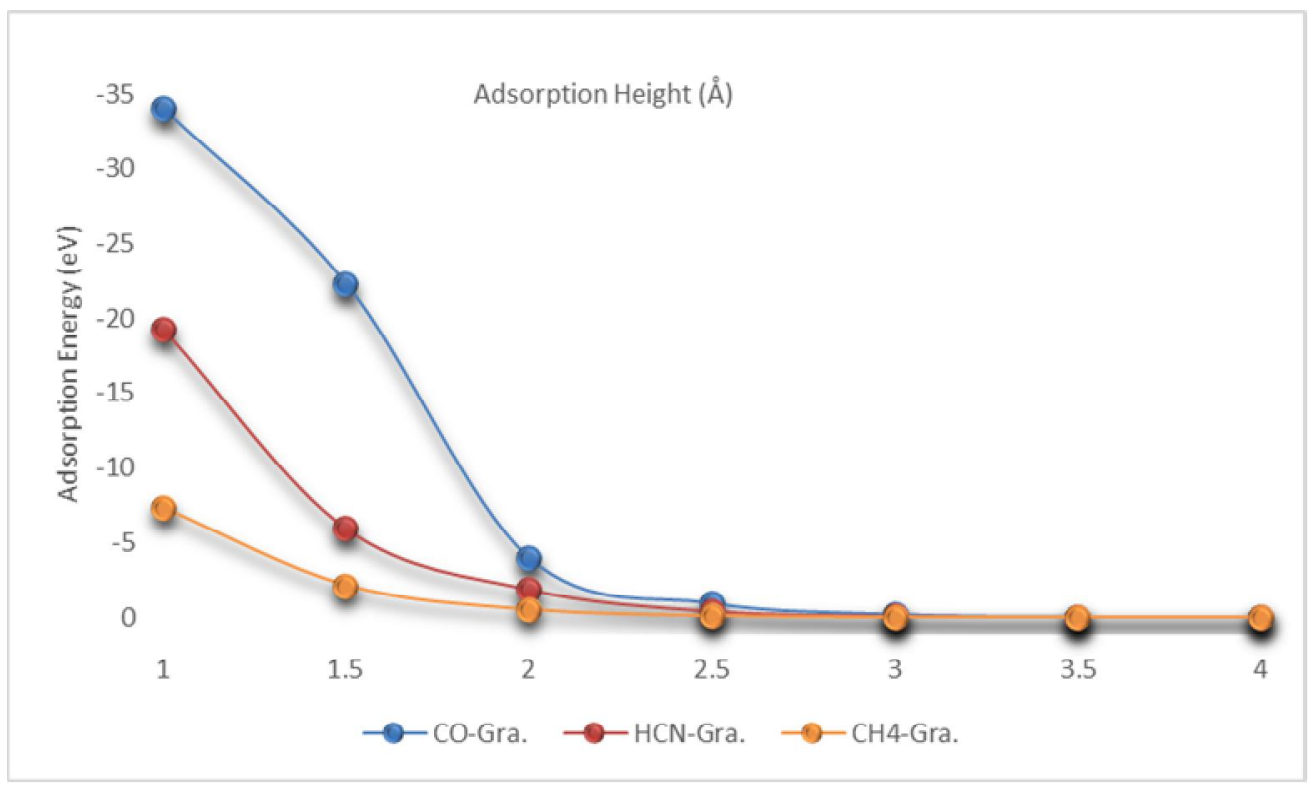

Figure 4: Represents adsorption curves for gases under study. 


\section{7- FT-IR SPECTRASCOPIC}

In this section study (FT-IR) spectroscopic to determine functional group for graphene before and after adsorption with gas molecule. FT-IR spectroscopy is important tool to determine chemical adsorption by appear the radical of gas adsorbed on surface of graphene nano-ribbon, it calculated using DFT at basis set 6-31G with hybrid function B3YLP. Pure graphene FT-IR analysis for $\mathrm{C}-\mathrm{H}$ bond appears at $3213 \mathrm{~cm}^{-1}$ in stretching vibration mode, C-H a skewsymmetric appears on $3199 \mathrm{~cm}^{-1}$ of methylene group, methylene group appear at $1351 \mathrm{~cm}^{-1}$ region of FT-IR spectrum approximately from $1349 \mathrm{~cm}^{-1}$ for study[27]. For $\mathrm{CO}$ adsorbed on surface of graphene ribbon appear new region in weak intensity is $\mathrm{C}-\mathrm{O}-\mathrm{C}$ at wave number 1239 $\mathrm{cm}^{-1}$ [28]. Resulting from contacted CO gas molecule with carbon atom in surface of graphene. $\mathrm{CH}_{4}$ adsorbed appear new reigon at wave number $(810-828) \mathrm{cm}^{-1}$ and $1458 \mathrm{~cm}^{-1}$ resulting from contacted methane molecule on surface of graphene ribbon. $\mathrm{HCN}$ gas molecule adsorbed $\mathrm{C}-\mathrm{N}$ triple bond appear at 2096 is exactly agreement with[29], appear new region at wave number 3480 resulting from chemical adsorption and finally regions at (864-928) at weak intensity. Figure (6) shows FT-IR spectra for systems under study.

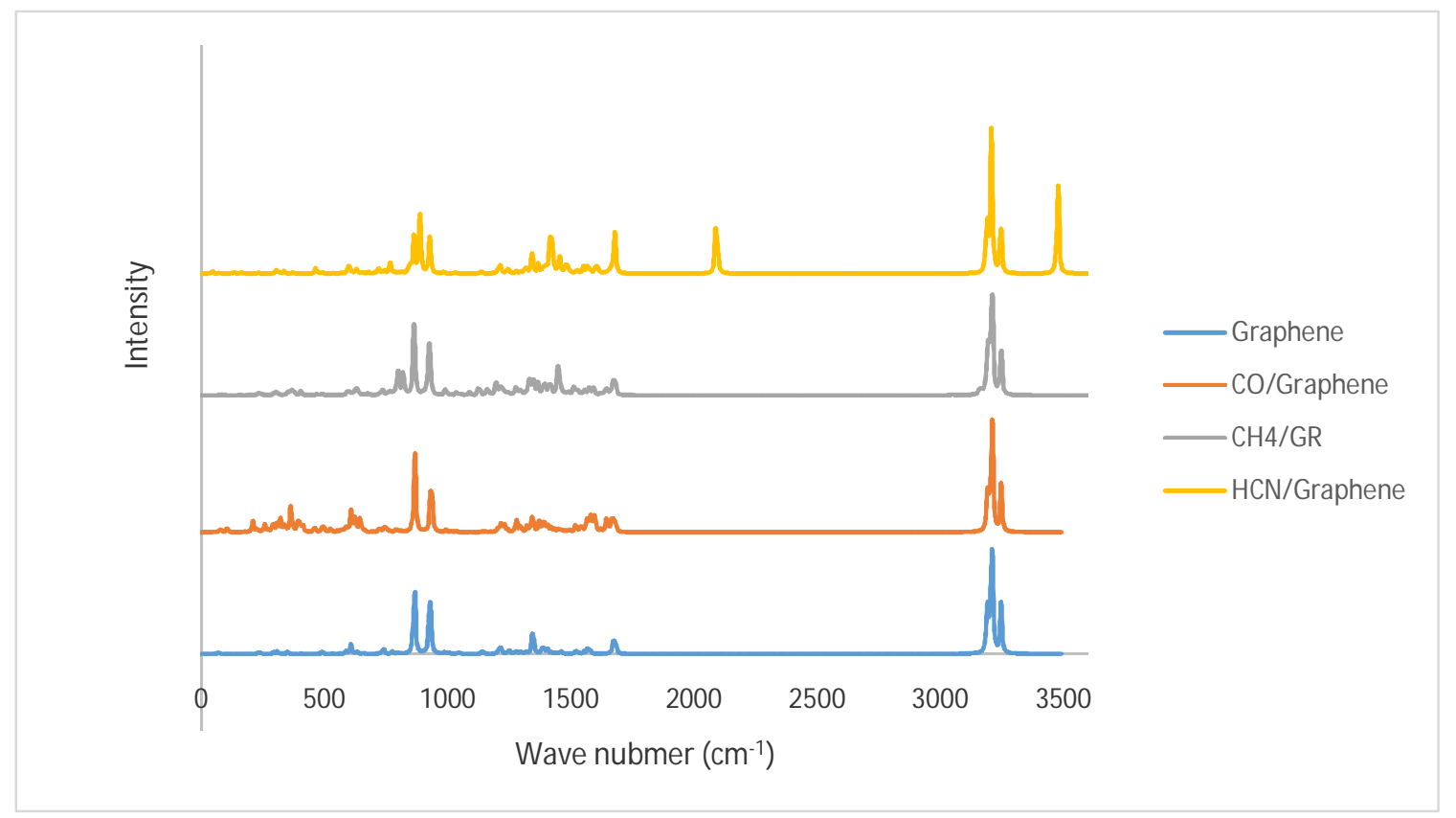

Figure 6: Shows FT-IR spectra for systems under study.

\section{8- UV-VISIABLE SPECTRA}

In this part of study effect of gas molecule on optical Properties for graphene nano-ribbon, determine type of shifting blue or red. Optical calculation is important part to determine type of shifting for adsorption gases on surface of graphene ribbon. TD-DFT method used to compute UV-Visible Properties at basis set 6-31G with hybrid function B3LYP. for pure graphene ribbon maximum absorbed wave length is equal (525.2) $\mathrm{nm}$. Figure (7) represents UV-Visible spectra for adsorbed gas molecule on surface of graphene nano-ribbon are $(\mathrm{CO}$,
$\mathrm{HCN}$ and $\mathrm{CH}_{4}$ ) respectively. Table (4) represent maximum wave length absorbed by adsorbed system. Result indicate that all UV-Visible spectra has a red shift. Some gases in chemical adsorption mechanism appear 2 and 3 transition state and this clear in distance 1 and $1.5 \AA$. Also results indicate when adsorption distance increase ability of interaction between gas molecule and surface decreased. The wave length of absorption decreased until fit on pure graphene nano-ribbon and this prove that interaction was vanishing[30-32].

Table 4: Represents max. absorption wave length of adsorption gas molecule.

\begin{tabular}{|c|c|c|c|}
\hline $\mathbf{D}(\AA)$ & $\lambda-\mathrm{CO}$ & $\lambda-\mathrm{HCN}$ & $\lambda-\mathrm{CH}_{4}$ \\
\hline 1 & $\begin{array}{c}562.84 \\
756.2 \\
1156.49\end{array}$ & $\begin{array}{c}816 \\
1135.98\end{array}$ & $\begin{array}{c}486 \\
556.55 \\
728.4 \\
\end{array}$ \\
\hline 1.5 & $\begin{array}{c}573.37 \\
681 \\
\end{array}$ & 706.23 & 540.45 \\
\hline 2 & 537.71 & 523.98 & 527.56 \\
\hline 2.5 & 527 & 524.98 & 525.65 \\
\hline 3 & 525.78 & $525 . .52$ & 525.21 \\
\hline 3.5 & 525.5 & 525.49 & 525.25 \\
\hline 4 & 525.44 & 525.46 & 525.20 \\
\hline
\end{tabular}


Hussein A. Madlool et al., International Journal of Emerging Trends in Engineering Research, 9(8), August 2021, 1170 - 1178
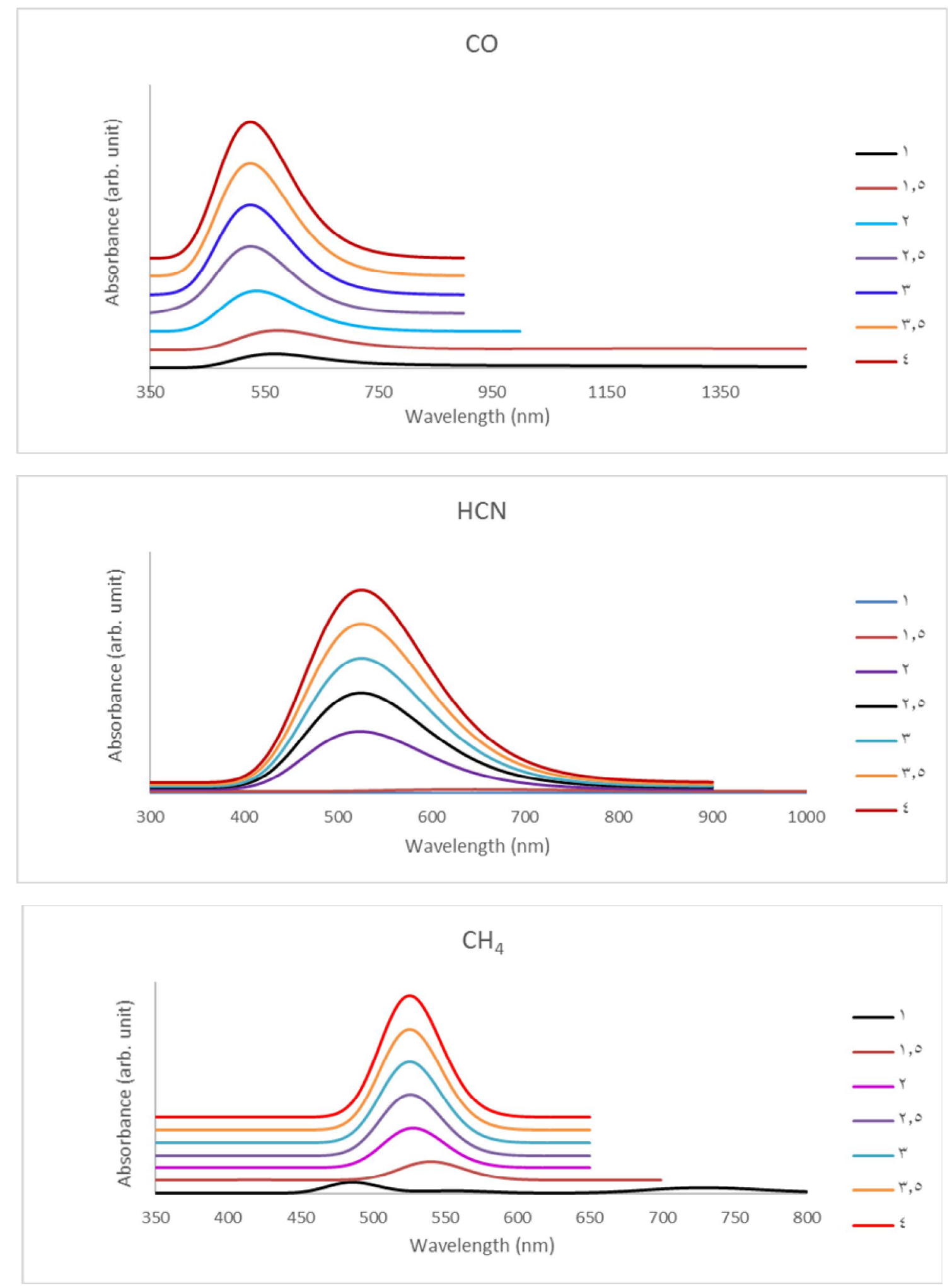

Figure 7: Represents UV-Visible curves as function of adsorption distance. 


\section{9- CONCLUSIONS}

In present report DFT calculation investigation ability of graphene nano materials to detection toxic gases that presence in atmosphere. Adsorption calculation shows that carbon mono oxide have high reactivity with surface of nano materials after it hydro cyanide and finally methane

\section{REFERANCESS}

[1] K. S. Novoselov et al., "Electric field effect in atomically thin carbon films," Science (80-. )., vol. 306, no. 5696, pp. 666-669, 2004.

[2] W. Zhang, J. Liu, Y. Sun, S. Gadipelli, X. Han, and G. Colantuono, "Effective Adsorbents for Establishing Solids Looping as a Next Generation NG PCC Technology."

[3] J. C. Meyer, A. K. Geim, M. I. Katsnelson, K. S. Novoselov, T. J. Booth, and S. Roth, "The structure of suspended graphene sheets," Nature, vol. 446, no. 7131, pp. 60-63, 2007.

[4] A. Bansil, H. Lin, and T. Das, "Colloquium: Topological band theory," Rev. Mod. Phys., vol. 88, no. 2, p. 21004, 2016.

[5] S. Kumar et al., "Femtosecond carrier dynamics and saturable absorption in graphene suspensions," Appl. Phys. Lett., vol. 95, no. 19, p. 191911, 2009.

[6] J. Kong et al., "Nanotube molecular wires as chemical sensors," Science (80-. )., vol. 287, no. 5453, pp. 622-625, 2000.

[7] P. E. Turner and S. Duffy, "Evolutionary ecology of multiple phage adsorption and infection," Bacteriophage Ecol. Popul. growth, Evol. impact Bact. viruses. Cambridge Univ. Press. Cambridge, 2008.

[8] D. M. Ruthven, "Fundamentals of adsorption equilibrium and kinetics in microporous solids," in Adsorption and diffusion, Springer, 2006, pp. 1-43.

[9] J. Rouquerol, F. Rouquerol, P. Llewellyn, G. Maurin, and K. S. W. Sing, Adsorption by powders and porous solids: principles, methodology and applications. Academic press, 2013.

[10] V. A. Lavrenko, I. A. Podchernyaeva, D. V Shchur, A. D. Zolotarenko, and A. D. Zolotarenko, "Features of physical and chemical adsorption during interaction of polycrystalline and nanocrystalline materials with gases," Powder Metall. Met. Ceram., vol. 56, no. 9, pp. 504-511, 2018.

[11] G. Crini and P.-M. Badot, "Application of chitosan, a natural aminopolysaccharide, for dye removal from aqueous solutions by adsorption processes using batch studies: A review of recent literature," Prog. Polym. Sci., vol. 33, no. 4, pp. 399-447, 2008.

[12] C. P. Bergmann and F. M. Machado, Carbon nanomaterials as adsorbents for environmental gases. Results show that also, chemical adsorption decreased with increasing distance between gas molecule and surface. Finally result show that ability to design chemical sensor for gases under study that used in environmental site. and biological applications. Springer, 2015.

[13] N. Domun, K. R. Paton, H. Hadavinia, T. Sainsbury, T. Zhang, and H. Mohamud, "Enhancement of fracture toughness of epoxy nanocomposites by combining nanotubes and nanosheets as fillers," Materials (Basel)., vol. 10, no. 10, p. 1179, 2017.

[14] J. Li, Y. Lu, Q. Ye, M. Cinke, J. Han, and M. Meyyappan, "Carbon nanotube sensors for gas and organic vapor detection," Nano Lett., vol. 3, no. 7, pp. 929-933, 2003.

[15] S. Peng and K. Cho, "Ab initio study of doped carbon nanotube sensors," Nano Lett., vol. 3, no. 4, pp. 513-517, 2003.

[16] Z. M. Ao, J. Yang, S. Li, and Q. Jiang, "Enhancement of $\mathrm{CO}$ detection in Al doped graphene," Chem. Phys. Lett., vol. 461, no. 4-6, pp. 276-279, 2008.

[17] P. Lazar et al., "Adsorption of small organic molecules on graphene," J. Am. Chem. Soc., vol. 135, no. 16, pp. 6372-6377, 2013.

[18] C. Christodoulou et al., "Tuning the electronic structure of graphene by molecular dopants: Impact of the substrate," ACS Appl. Mater. Interfaces, vol. 7, no. 34, pp. 19134-19144, 2015.

[19] S. Novikov, N. Lebedeva, and A. Satrapinski, "Ultrasensitive NO2 gas sensor based on epitaxial graphene," J. Sensors, vol. 2015, 2015.

[20] S. Sharma and A. S. Verma, "A theoretical study of $\mathrm{H} 2 \mathrm{~S}$ adsorption on graphene doped with $\mathrm{B}$, Al and Ga," Phys. B Condens. Matter, vol. 427, pp. 12-16, 2013.

[21] S. F. Rastegar, A. A. Peyghan, and N. L. Hadipour, "Response of Si-and Al-doped graphenes toward HCN: a computational study," Appl. Surf. Sci., vol. 265, pp. 412-417, 2013.

[22] X.-P. Chen et al., "Density-functional calculation of methane adsorption on graphenes," IEEE Electron Device Lett., vol. 36, no. 12, pp. 13661368, 2015.

[23] E. Vessally, M. D. Esrafili, R. Nurazar, P. Nematollahi, and A. Bekhradnia, "A DFT study on electronic and optical properties of aspirinfunctionalized $\quad \mathrm{B} \quad \mathbf{1 2} \mathrm{N} \quad 12$ fullerene-like nanocluster," Struct. Chem., vol. 28, no. 3, pp. 735-748, 2017.

[24] M. A. Al-Seady, E. Ahmed, H. M. Abduljalil, and A. A. Kahewish, "Studying the adsorption energy of $\mathrm{CO}$ gas molecule in different nanosystems using density function theory," Egypt. $J$. 
Hussein A. Madlool et al., International Journal of Emerging Trends in Engineering Research, 9(8), August 2021, 1170 - 1178

Chem., vol. 64, no. 5, pp. 2607-2612, 2021.

[25] R. Majidi, A. R. Karami, K. Rahmani, and A. M. Khairogli, "Electronic properties of hydrogenated porous Graphene based nanoribbons: A density functional theory study," Int. J. Nano Dimens., vol. 11, no. 2, pp. 112-119, 2020.

[26] J. Beheshtian, Z. Bagheri, M. Kamfiroozi, and A. Ahmadi, "A theoretical study of CO adsorption on aluminum nitride nanotubes," Struct. Chem., vol. 23, no. 3, pp. 653-657, 2012.

[27] A. Heidari, J. Esposito, and A. Caissutti, "Ciguatoxin time-resolved absorption and resonance FT-IR and raman biospectroscopy and density functional theory (DFT) investigation of vibronic-mode coupling structure in vibrational spectra analysis," 2019.

[28] S. Maarof, A. A. Ali, and A. M. Hashim, "Molecular structures of cooking palm oil in gas phase modelled by density functional theory," Mater. Today Proc., vol. 7, pp. 770-775, 2019.

[29] V. Ţucureanu, A. Matei, and A. M. Avram, "FTIR spectroscopy for carbon family study," Crit. Rev. Anal. Chem., vol. 46, no. 6, pp. 502-520, 2016.

[30] N. Osouleddini and S. F. Rastegar, "DFT study of the $\mathrm{CO} 2$ and $\mathrm{CH} 4$ assisted adsorption on the surface of graphene," J. Electron Spectros. Relat. Phenomena, vol. 232, pp. 105-110, 2019.

[31] O. Leenaerts, B. Partoens, and F. M. Peeters, "Adsorption of $\mathrm{H} 2 \mathrm{O}, \mathrm{N} \mathrm{H} 3, \mathrm{CO}, \mathrm{N} \mathrm{O}$, and NO on graphene: A first-principles study," Phys. Rev. B, vol. 77, no. 12, p. 125416, 2008.

[32] A. S. Rad, H. Pazoki, S. Mohseni, D. Zareyee, and M. Peyravi, "Surface study of platinum decorated graphene towards adsorption of NH3 and CH4," Mater. Chem. Phys., vol. 182, pp. 3238, 2016. 